\title{
Perioperative chemotherapy with pemetrexed and cisplatin for pulmonary large-cell neuroendocrine carcinoma: a case report and literature review
}

This article was published in the following Dove Press journal:

OncoTargets and Therapy

\section{Hong Tang' \\ Hongyan Wang' \\ Shaoyan $\mathrm{Xi}^{2}$ \\ Chunyu $\mathrm{He}^{3}$ \\ Yuxi Chang ${ }^{4}$ \\ Qiming Wang' \\ Yufeng Wu'}

'Department of Internal Medicine, Affiliated Cancer Hospital of Zhengzhou University, Henan Cancer Hospital, Zhengzhou, Henan, People's Republic of China; ${ }^{2}$ Department of Pathology, Sun Yat-sen University Cancer Center, Guangzhou, Guangdong, People's Republic of China; ${ }^{3}$ Department of Radiation Oncology, Affiliated Cancer Hospital of Zhengzhou University, Henan Cancer Hospital, Zhengzhou, Henan, People's Republic of China;

${ }^{4}$ Department of Pathology, Affiliated Cancer Hospital of Zhengzhou University, Henan Cancer Hospital, Zhengzhou, Henan, People's Republic of China
Correspondence: Yufeng Wu Department of Internal Medicine, Affiliated Cancer Hospital of Zhengzhou University, Henan Cancer Hospital, 127 Dong Ming Road, Zhengzhou, Henan, People's Republic of China

Tel +86I8695829280

Email yufengwu@vip.qq.com
Background: Pulmonary large-cell neuroendocrine carcinoma (LCNEC) is associated with poor prognosis, and its treatment strategy is still controversial, especially regarding chemotherapy regimens.

Case report: We present the case of a 49 -year-old Chinese male with primary pulmonary LCNEC treated with neoadjuvant and adjuvant chemotherapy with cisplatin plus pemetrexed. A suspected quasi-circular mass in the left lower pulmonary lobe and an enlarged mediastinal lymph node were found. The patient was diagnosed with adenocarcinoma with neuroendocrine differentiation based on computerized tomography-guided percutaneous lung biopsy. An EGFR gene mutation test showed negative results. Cisplatin and pemetrexed were administered as the neoadjuvant chemotherapy regimen. The primary lesion had reduced markedly, and the enlarged mediastinal lymph node had disappeared after two cycles of neoadjuvant chemotherapy. A left lower lobectomy and mediastinal lymph node dissection were performed. The lesion was confirmed as LCNEC based on postoperative histopathological analysis and immunohistochemical results. The patient underwent four cycles of adjuvant chemotherapy with cisplatin and pemetrexed for a month postoperatively, followed by postoperative adjuvant radiotherapy. The patient was still alive after a follow-up of 24 months, with no evidence of tumor recurrence.

Conclusion: Cisplatin combined with pemetrexed is effective and safe for patients with pulmonary LCNEC.

Keywords: large-cell neuroendocrine carcinoma, pulmonary tumor, cisplatin, pemetrexed

\section{Introduction}

Neuroendocrine tumors (NETs) are categorized into typical carcinoids, atypical carcinoids, small-cell lung cancer (SCLC), and large-cell neuroendocrine carcinoma (LCNEC) in accordance with morphological and biological features. Pulmonary LCNEC, a subtype of non-small-cell lung cancer (NSCLC) by definition, was first introduced as a variant of large-cell carcinoma (LCC) in 1999 by the World Health Organization (WHO). Pulmonary LCNEC is a rare entity in NSCLC known for its poor prognosis, and accounts for $\sim 3 \%$ of all pulmonary malignancies. ${ }^{1-5}$ As has been described in many reports, the 5-year survival rate of LCNEC after surgical resection is much worse than that of other histological variants of NSCLC. ${ }^{3-8}$ However, for survival time, LCNEC is closer to SCLC. A Japanese study with a large sample size demonstrated no difference in prognosis between LCNEC and SCLC ${ }^{8}$

There may be some clinicopathological differences between LCNEC and SCLC in terms of periphery, size, and grade in NETs, ${ }^{9}$ but several studies reveal that LCNEC 
is similar to SCLC in clinical characteristics and morphology, including a preponderance of males and smokers. ${ }^{8,10-12}$ Furthermore, it is difficult to distinguish the comparable genetic alteration in LCNEC from SCLC, as reported by Jones et al. ${ }^{13}$ In addition to histological similarities, LCNEC is similar to SCLC in recurrence rate after radical resection, even at an early stage. Therefore, treatment strategy for LCNEC remains a source of controversy at present. ${ }^{14}$ Most chemotherapeutic regimens are formulated based on etoposide combined with cisplatin or carboplatin. ${ }^{15-19}$ Pemetrexed combined with platinum is rarely reported to be used in perioperative chemotherapy for pulmonary LCNEC. A patient with stage IIIA pulmonary LCNEC who received pemetrexed combined with platinum in perioperative chemotherapy, is presented in this article. Clinicopathological features of the patient with pulmonary LCNEC are described in this article, and he achieved remarkable therapeutic efficacy using pemetrexed with cisplatin. Written informed consent was obtained from the patient to have their case details and any accompanying images published.

\section{Case report}

A 49-year-old man was admitted with a suspected mass in the left lower pulmonary lobe found during health examination. The patient was a smoker with no family history of cancer. Chest computerized tomography (CT) (Figure 1) showed a quasi-circular mass $(25.1 \times 22.2 \mathrm{~mm})$ in the left lower pulmonary lobe, together with an enlarged mediastinal lymph node $(7.7 \mathrm{~mm})$. The patient underwent CT-guided percutaneous biopsy in the left lung neoplasm. Pathological analysis revealed a poorly differentiated adenocarcinoma with neuroendocrine differentiation (Figure 2A). Immunohistochemistry showed positive staining of cytokeratin (CK), with CK7 and Ki-67 index of $60 \%$, but negative staining of
P63 and thyroid transcription factor-1 (Figure 2B-F). The discovered serum tumor markers included carcinoembryonic antigen $(3.67 \mathrm{ng} / \mathrm{mL}$ ), neuron-specific enolase (NSE; $19.36 \mathrm{ng} / \mathrm{mL}$ ), and circulating cytokeration 19 fragments (CYFRA21-1; $2.15 \mathrm{ng} / \mathrm{mL}$ ). Molecular analyses of exons $18,19,20$, and 21 of $E G F R$ revealed no mutation.

The patient was diagnosed with clinical stage IIIA (T1bN2M0) pulmonary adenocarcinoma with mediastinal lymph node metastasis. Optimal management requires both local and systemic disease controls; as a result, treatment for clinical stage IIIA (N2) NSCLC has been one of the most controversial topics in Thoracic Oncology. Neoadjuvant chemotherapy and/or radiotherapy prior to surgical resection has been demonstrated to provide better progression-free survival (PFS) than definitive chemoradiotherapy for patients with stage IIIA (N2) NSCLC, in several reports. ${ }^{20,21}$ The tumor was technically resectable, which involved single-zone mediastinal node. Therefore, neoadjuvant chemotherapy was selected, with an aim to induce tumor downstaging, thus facilitating and simplifying the subsequent surgical treatment. After a multidisciplinary team meeting, the patient proceeded to undergo two cycles of neoadjuvant chemotherapy with pemetrexed $\left(500 \mathrm{mg} / \mathrm{m}^{2}\right.$ on day 1 , every 3 weeks) and cisplatin ( $25 \mathrm{mg} / \mathrm{m}^{2}$ from days 1 to 3 , every 3 weeks) from March to April 2015. Side effects were limited to grade 1 fatigue and grade 1 nausea. Chest CT scan in May 2015 showed that the left lower lobe tumor had significantly reduced to $12.7 \times 7.4 \mathrm{~mm}$ in size, and the enlarged mediastinal lymph node almost disappeared (Figure 3). The patient achieved partial remission (PR) after neoadjuvant chemotherapy.

The patient underwent left lower radical lobectomy completely (R0) resection and mediastinal lymph node dissection in video-assisted thoracoscopic surgery in May 2015. The postoperative sample was confirmed as pT1aN2M0 LCNEC
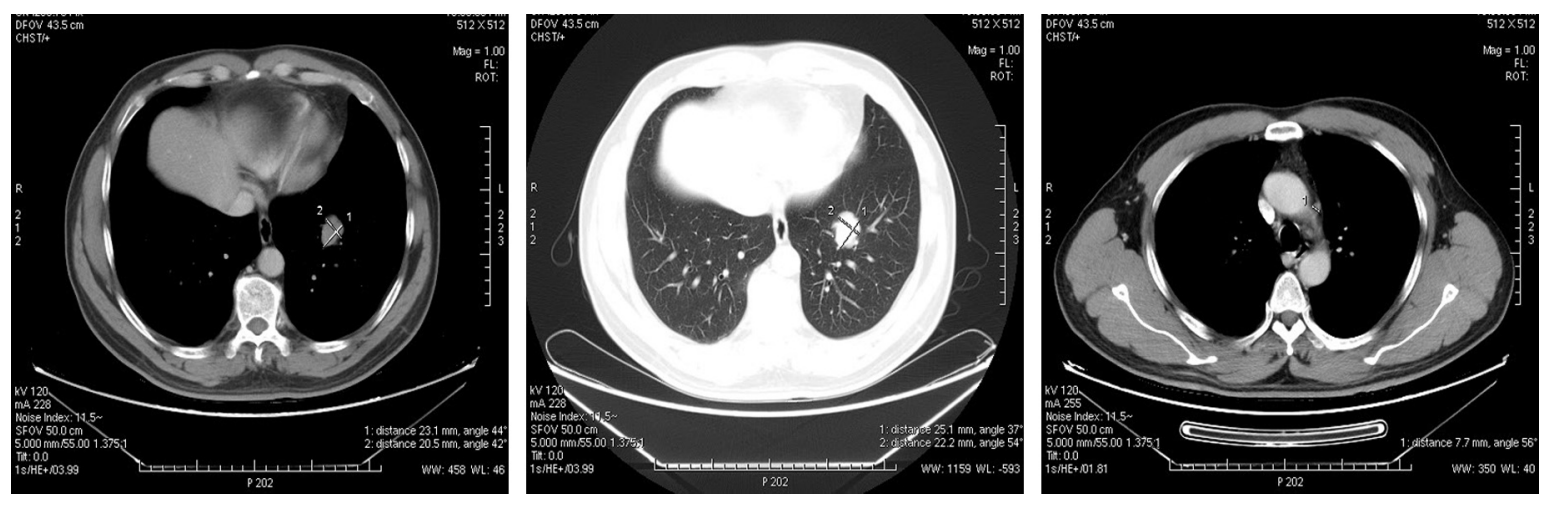

Figure I Prior to neoadjuvant chemotherapy, computerized tomography images of chest in March 2015 indicated a quasi-circular mass in the left lower pulmonary lobe, together with an enlarged mediastinal lymph node. 

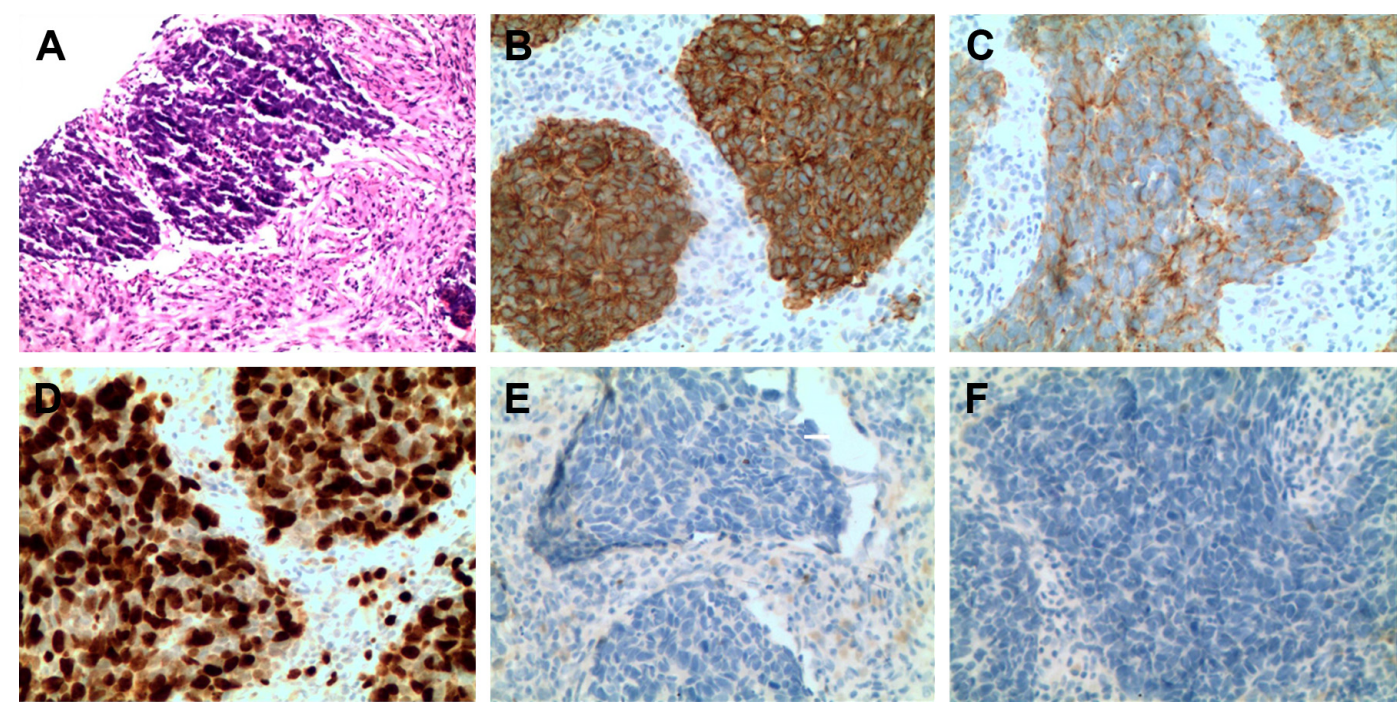

Figure 2 Histopathological examination of the biopsy specimen revealed a poorly differentiated adenocarcinoma with neuroendocrine differentiation (A, $\times 100)$, immunohistochemical staining for CK (B, $\times 200)$, CK7 (C, $\times 200)$, Ki-67 (D, $\times 200)$, P63 (E, $\times 200)$, and transcription factor-I (F, $\times 200)$.

Abbreviation: $\mathrm{CK}$, cytokeratin.

upon pathological examination. Immunohistochemical analysis (Figure 4) demonstrated intense immunoreactivity of CK, CK7, as well as NSE, chromogranin-A (CgA), and cluster of differentiation 56 (CD56), which was a typical LCNEC component. Immunohistochemistry showed focally positive results of synaptophysin (SyN), and negative results of P63, P40, and NapsinA. No surgery-related complications occurred. Chest CT scan 1 month after surgical resection revealed no tumor recurrence (Figure 5A and B).

The patient convalesced well after surgery and received adjuvant chemotherapy of the same regimen for four cycles. Meanwhile, sequential postoperative radiotherapy (PORT) at a total radiation dose of 45 Gy was given, which was divided into a daily dose of 1.5 Gy for twice after surgery for a month. The patient is followed up by tumor marker every month, and CT scan every 2 months. No evidence of recurrence has been detected during the 24-month follow-up after surgery (Figure 5C and D).

\section{Discussion}

LCNEC is previously classified as a subtype of LCC, which is considered as a part of pulmonary NET spectrum. ${ }^{22-24}$ Diagnostic criteria for LCNEC have been revised in the 4th WHO Classification (2015), in which LCNEC is moved from the LCC chapter to the NET chapter. ${ }^{25,26}$ As LCNEC is a poorly recognized entity that is underdiagnosed, it is frequently mistaken for poorly differentiated NSCLC, atypical carcinoid, or intermediate cell-type SCLC. ${ }^{3,15,27,28}$ Patient in this case is diagnosed with lung adenocarcinoma with neuroendocrine differentiation based on CT-guided percutaneous
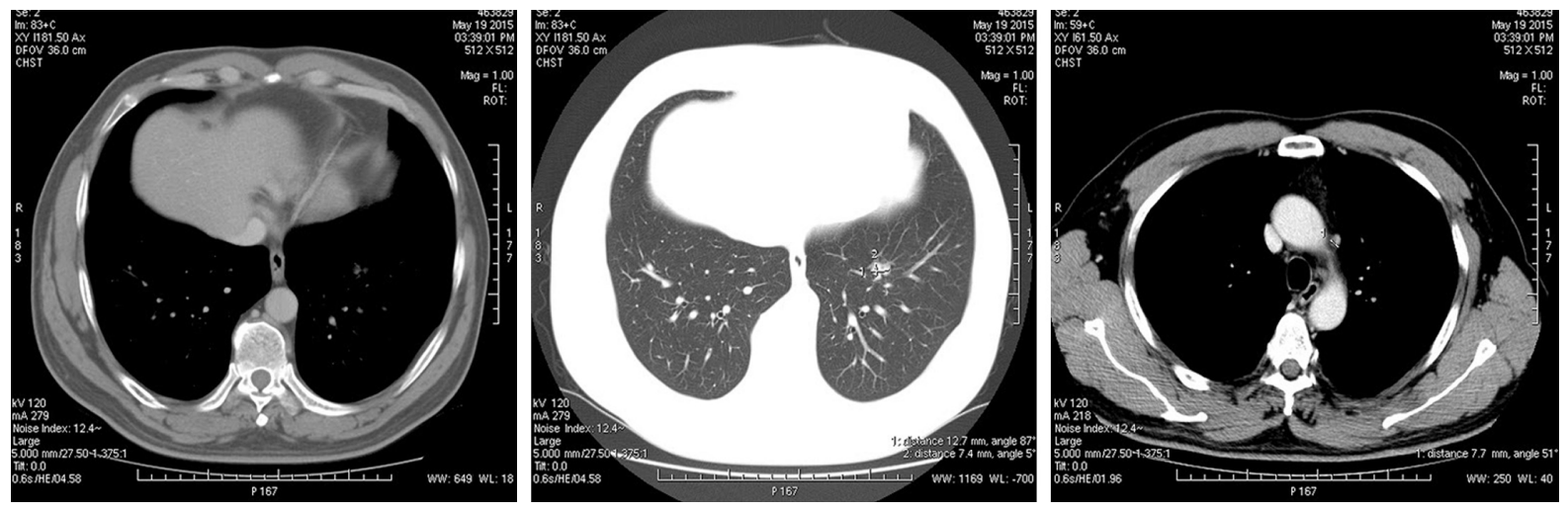

Figure 3 After two cycles of pemetrexed with cisplatin neoadjuvant chemotherapy, computerized tomography images of chest in May 2015 indicated that the left lower lobe tumor shrank significantly than before and the enlarged mediastinal lymph node almost disappeared. 

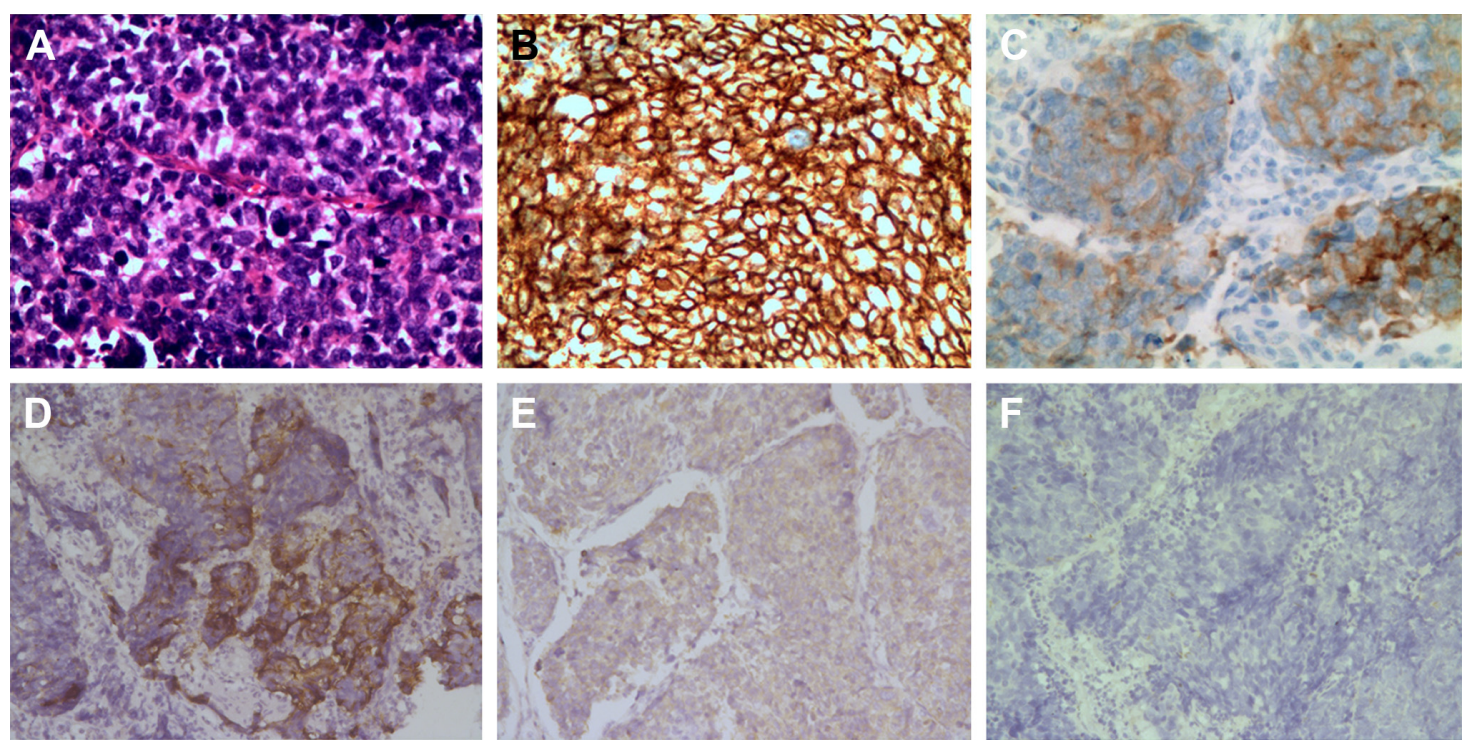

Figure 4 Histopathological examination of surgical specimens revealed LCNEC.

Notes: H\&E staining for specimens $(\mathbf{A}, \times 200)$ and immunohistochemical staining for CD56 $(\mathbf{B}, \times 200)$, synaptophysin $(\mathbf{C}, \times 200)$, chromogranin-A (D, $\times 200)$, neuron-specific enolase $(\mathbf{E}, \times 200)$, and $\operatorname{Napsin} A(\mathbf{F}, \times 200)$.

Abbreviations: CD56, cluster of differentiation 56; LCNEC, large-cell neuroendocrine carcinoma.

biopsy before surgery. The obscure morphology of NET, together with the occasional coexistence of other histological types, is responsible for misdiagnosis, especially in the case of cytology or small biopsy sample. ${ }^{28}$

LCNEC and SCLC share the same characteristics in terms of neuroendocrine morphology shown as follows: 1) neuroendocrine morphology, such as organoid nesting, nuclear palisading, rosettes, and trabecular pattern; 2) a high mitotic rate of at least 11 per $2 \mathrm{~mm}^{2}$ (10 high-power fields); and 3) large areas of tumor necrosis. However, LCNEC also has the cytological features of NSCLC, including large cell size, low ratio of nuclear to cytoplasm volume, vesicular or
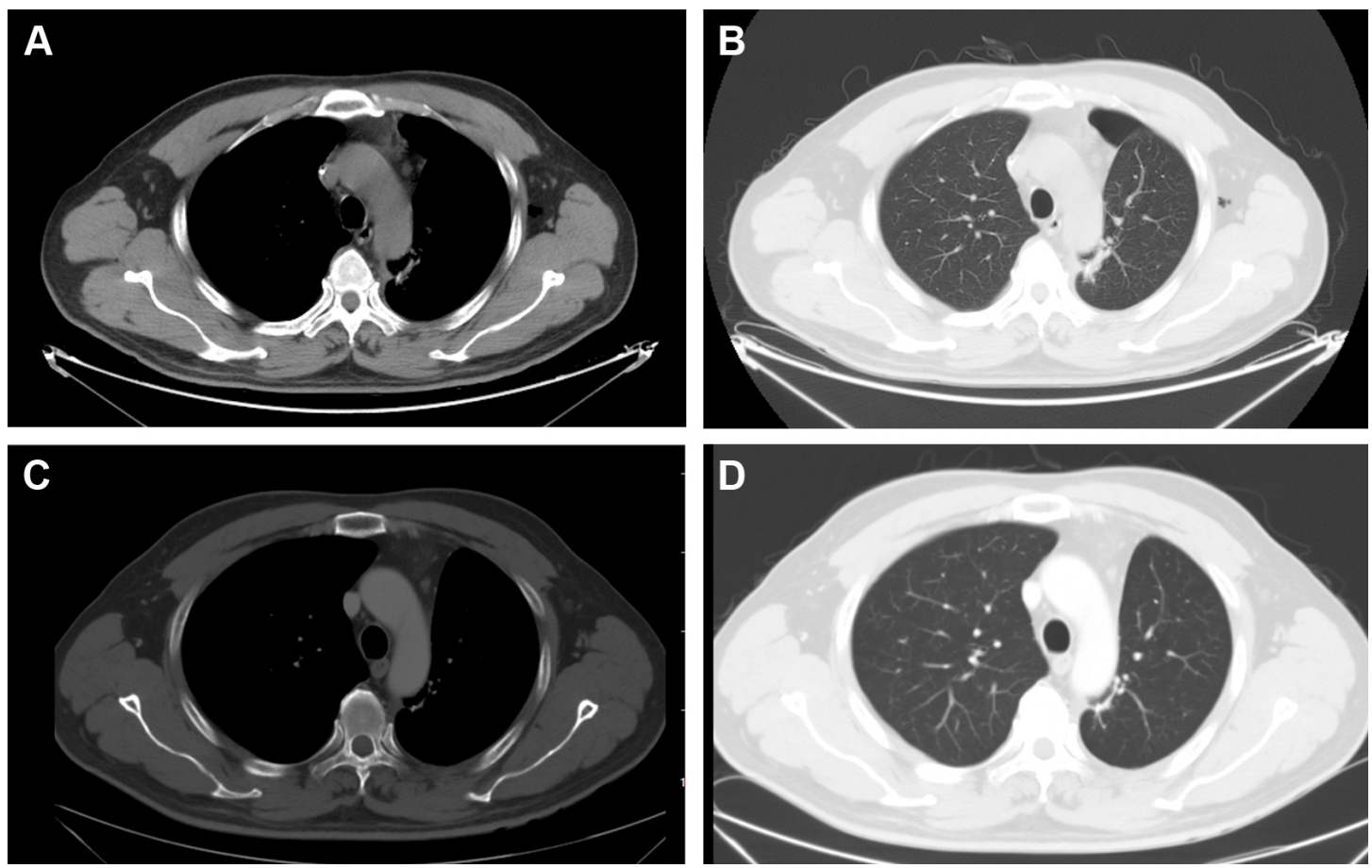

Figure 5 Computerized tomography images of chest indicated that no evidence of recurrence has been detected during the 24-month follow-up. (A and B) Images in June 2015; (C and D) Images in March 2017. (A and $\mathbf{C}$ ) Images of vertical window; (B and $\mathbf{D})$ ): images of lung window. 
fine chromatin, or frequent nucleoli, or a combination of these features, which are different from SCLC. The immunohistochemical analysis of neuroendocrine markers is mandatory to establish a reliable diagnosis of LCNEC. Neuroendocrine differentiation in other lung cancers, for example, adenocarcinomas, is thought to be a predictor of worse survival. ${ }^{29}$ LCNEC must be confirmed by an argyrophilic reaction or immunopositive results of $\mathrm{CgA}$, SyN, or CD56. ${ }^{30,31}$ The awareness of this rare entity among pathologists, together with an increased application of immunohistochemical neuroendocrine markers, such as $\mathrm{CD} 56, \mathrm{SyN}$, and $\mathrm{CgA}$, in routine diagnostics has improved the diagnostic rate of LCNEC in recent years. Thus, obtaining biopsy sample that is sufficient in size is essential for accurate pathological diagnosis.

The patient diagnosed with pulmonary LCNEC with mediastinal lymph node metastasis is successfully treated with surgery and perioperative chemotherapy with pemetrexed and cisplatin. Today, owing to the lack of literature data related to these neoplasms and because of their peculiar features, the best treatment strategy for this group of malignancies remains unclear. Primary surgery should be the preferred choice for operable patients with pulmonary LCNEC, which also represents the principal method for accurate diagnosis. In addition, lobectomy or pneumonectomy with a systematic nodal dissection is the preferred choice as it may prolong survival. ${ }^{7}$ Furthermore, it was demonstrated in a retrospective study that surgical treatment can achieve satisfactory results in early tumor stages, which are comparable with other NSCLCs, with a low perioperative mortality rate, ${ }^{29}$ but, the 5 -year survival in patients at stage III was only $29.7 \%$ and the presence of lymph node metastasis was also associated with a worse 5-year survival. Therefore, radical surgery is recommended but does not seem to be sufficient for resectable pulmonary LCNEC.

Perioperative chemotherapy has been demonstrated to bring survival benefit for patients with pulmonary LCNEC, as is shown in some retrospective studies with small sample size. Perioperative chemotherapy is recommended even for patients with resectable stage I LCNEC due to its characteristics such as aggressiveness, high potential for metastasis, and remarkably dismal prognosis. ${ }^{6,32-34}$ However, no randomized clinical trial investigating the optimal treatment of LCNEC is available up to now. Malapelle et $\mathrm{al}^{35}$ suggest that CCDC6 and USP7 have a predictive value for the clinical usage of USP7 inhibitors in combination with the PARP inhibitors in L-NET in addition to standard therapy. Iyoda et $\mathrm{al}^{33,36}$ confirmed the superiority of platinum-base adjuvant chemotherapy over nonplatinum adjuvant chemotherapy or nonadjuvant therapy. A pilot study has applied adjuvant chemotherapy in treating completely removed high-grade pulmonary neuroendocrine carcinoma, which includes LCNEC and SCLC. Our results indicate that chemotherapy regimens with irinotecan and cisplatin result in the 3-year relapse-free survival of $74 \%$ and the 3 -year OS of $86 \%$ among LCNEC, ${ }^{37}$ but the authors did not elaborate on the median PFS and OS, especially the PFS and OS for patients with IIIA. Meanwhile, nedaplatin combined with irinotecan is also effective and safe for patients with pulmonary LCNEC..$^{38}$ Most of the chemotherapy regimens for LCNEC in these studies have adopted the chemotherapy regimens for SCLC. It was reported in the latest clinical study by Kim et al that the median PFS was 11.9 months of resectable LCNEC whose chemotherapy regimens were intravenous paclitaxel, docetaxel with cisplatin, or carboplatin, and the PFS was significantly improved in this case compared to those patients without adjuvant chemotherapy. It was also demonstrated in this study that in patients with pathological stage II or higher, those who underwent adjuvant treatment showed significantly better 5-year OS rates and 5-year DFS rates. The OS and DFS for patients with IIIA were only $\sim 3$ and 1 year, respectively. ${ }^{39}$

Pemetrexed is a TS inhibitor, which can inhibit TS, thus leading to futile cycles of misincorporation of Dump, excision repair, and ATP depletion. ${ }^{40,41}$ TS has been recognized as a target in Oncology since the synthesis of fluoropyrimidines in $1957 . .^{42}$ Pemetrexed, which has comparable efficacy and significantly lowered toxicity, has now become a gold standard in first-line maintenance and second-line treatment for patients with nonsquamous NSCLC. ${ }^{43-45}$ Several studies have shown that TS level varies from histology to histology. Lower TS expression level is seen in adenocarcinoma and nonneuroendocrine LCC, while higher level can be observed in squamous and LCNEC and the highest level can be seen in SCLC. ${ }^{46-49}$ Patient in this case has biopsy-proven adenocarcinoma before operation; as a result, pemetrexed and cisplatin are used as the neoadjuvant chemotherapy. The patient achieves PR in accordance with Response Evaluation Criteria in Solid Tumor (RECIST) (Version 1.0). No treatment-related complications are seen in the patient during perioperative adjuvant chemotherapy and PORT. Furthermore, the patient has a better prognosis with at least 2 years without recurrence. Pemetrexed combined with cisplatin is confirmed to be inferior to etoposide combined with cisplatin in SCLC,${ }^{50}$ but its efficacy in LCNEC remains uncertain. Therefore, it is necessary to conduct prospective randomized trials to identify its therapeutic efficacy. 
To the best of our knowledge, this is the first report regarding perioperative adjuvant chemotherapy with pemetrexed and cisplatin for pulmonary LCNEC.

\section{Acknowledgments}

This work was supported by grants from the Key Science and Technology Research Foundation of Henan Province (number 152102410087 to Hong Tang), Ph.D. Research Foundation of Henan Cancer Hospital (number 201511004 to Yufeng Wu), and Henan Natural Science Foundation (numbers 182300410376 and 182300410297). The abstract of the paper has been published in the Journal of Thoracic Oncology, November 2017, volume 12, issue 11, supplement 2, page S2085.

\section{Disclosure}

The authors report no conflicts of interest in this work.

\section{References}

1. Travis WD, Linnoila RI, Tsokos MG, et al. Neuroendocrine tumors of the lung with proposed criteria for large-cell neuroendocrine carcinoma. An ultrastructural, immunohistochemical, and flow cytometric study of 35 cases. Am J Surg Pathol. 1991;15(6):529-553.

2. Dresler CM, Ritter JH, Patterson GA, Ross E, Bailey MS, Wick MR. Clinical-pathologic analysis of 40 patients with large cell neuroendocrine carcinoma of the lung. Ann Thorac Surg. 1997;63(1):180-185.

3. Takei H, Asamura H, Maeshima A, et al. Large cell neuroendocrine carcinoma of the lung: a clinicopathologic study of eighty-seven cases. J Thorac Cardiovasc Surg. 2002;124(2):285-292.

4. Paci M, Cavazza A, Annessi V, et al. Large cell neuroendocrine carcinoma of the lung: a 10-year clinicopathologic retrospective study. Ann Thorac Surg. 2004;77(4):1163-1167.

5. Veronesi G, Morandi U, Alloisio M, et al. Large cell neuroendocrine carcinoma of the lung: a retrospective analysis of 144 surgical cases. Lung Cancer. 2006;53(1):111-115.

6. Iyoda A, Hiroshima K, Toyozaki T, Haga Y, Fujisawa T, Ohwada H. Clinical characterization of pulmonary large cell neuroendocrine carcinoma and large cell carcinoma with neuroendocrine morphology. Cancer. 2001;91(11):1992-2000.

7. Zacharias J, Nicholson AG, Ladas GP, Goldstraw P. Large cell neuroendocrine carcinoma and large cell carcinomas with neuroendocrine morphology of the lung: prognosis after complete resection and systematic nodal dissection. Ann Thorac Surg. 2003;75(2):348-352.

8. Asamura H, Kameya T, Matsuno Y, et al. Neuroendocrine neoplasms of the lung: a prognostic spectrum. J Clin Oncol. 2006;24(1):70-76.

9. Isaka M, Nakagawa K, Ohde Y, et al. A clinicopathological study of peripheral, small-sized high-grade neuroendocrine tumours of the lung: differences between small-cell lung carcinoma and large-cell neuroendocrine carcinoma. Eur J Cardiothorac Surg. 2012;41(4):841-846.

10. Travis WD, Rush W, Flieder DB, et al. Survival analysis of 200 pulmonary neuroendocrine tumors with clarification of criteria for atypical carcinoid and its separation from typical carcinoid. Am J Surg Pathol. 1998;22(8):934-944.

11. Iyoda A, Hiroshima K, Baba M, Saitoh Y, Ohwada H, Fujisawa T. Pulmonary large cell carcinomas with neuroendocrine features are high-grade neuroendocrine tumors. Ann Thorac Surg. 2002;73(4):1049-1054.

12. Peng WX, Sano T, Oyama T, Kawashima O, Nakajima T. Large cell neuroendocrine carcinoma of the lung: a comparison with large cell carcinoma with neuroendocrine morphology and small cell carcinoma. Lung Cancer. 2005;47(2):225-233.
13. Jones MH, Virtanen C, Honjoh D, et al. Two prognostically significant subtypes of high-grade lung neuroendocrine tumours independent of small-cell and large-cell neuroendocrine carcinomas identified by gene expression profiles. Lancet. 2004;363(9411):775-781.

14. Iyoda A, Hiroshima K, Nakatani Y, Fujisawa T. Pulmonary large cell neuroendocrine carcinoma: its place in the spectrum of pulmonary carcinoma. Ann Thorac Surg. 2007;84(2):702-707.

15. Rossi G, Cavazza A, Marchioni A, et al. Role of chemotherapy and the receptor tyrosine kinases KIT, PDGFRalpha, PDGFRbeta, and Met in large-cell neuroendocrine carcinoma of the lung. J Clin Oncol. 2005;23(34):8774-8785.

16. Kozuki T, Fujimoto N, Ueoka H, et al. Complexity in the treatment of pulmonary large cell neuroendocrine carcinoma. J Cancer Res Clin Oncol. 2005;131(3):147-151.

17. Yamazaki S, Sekine I, Matsuno Y, et al. Clinical responses of large cell neuroendocrine carcinoma of the lung to cisplatin-based chemotherapy. Lung Cancer. 2005;49(2):217-223.

18. Embry JR, Kelly MG, Post MD, Spillman MA. Large cell neuroendocrine carcinoma of the cervix: prognostic factors and survival advantage with platinum chemotherapy. Gynecol Oncol. 2011;120(3):444-448.

19. Le Treut J, Sault MC, Lena H, et al. Multicentre phase II study of cisplatin-etoposide chemotherapy for advanced large-cell neuroendocrine lung carcinoma: the GFPC 0302 study. Ann Oncol. 2013; 24(6):1548-1552.

20. Gilligan D, Nicolson M, Smith I, et al. Preoperative chemotherapy in patients with resectable non-small cell lung cancer: results of the MRC LU22/NVALT 2/EORTC 08012 multicentre randomised trial and update of systematic review. Lancet. 2007;369(9577):1929-1937.

21. Thomas M, Rube C, Hoffknecht P, et al. Effect of preoperative chemoradiation in addition to preoperative chemotherapy: a randomised trial in stage III non-small-cell lung cancer. Lancet Oncol. 2008;9(7): 636-648.

22. Rekhtman N. Neuroendocrine tumors of the lung: an update. Arch Pathol Lab Med. 2010;134(11):1628-1638.

23. Varlotto JM, Medford-Davis LN, Recht A, et al. Should large cell neuroendocrine lung carcinoma be classified and treated as a small cell lung cancer or with other large cell carcinomas? J Thorac Oncol. 2011; 6(6):1050-1058.

24. Younossian AB, Brundler MA, Totsch M. Feasibility of the new WHO classification of pulmonary neuroendocrine tumours. Swiss Med Wkly. 2002;132(37-38):535-540.

25. Gibbs AR, Thunnissen FB. Histological typing of lung and pleural tumours: third edition. J Clin Pathol. 2001;54(7):498-499.

26. Travis WD, Brambilla E, Nicholson AG, et al. The 2015 World Health Organization classification of lung tumors: impact of genetic, clinical and radiologic advances since the 2004 classification. J Thorac Oncol. 2015;10(9):1243-1260.

27. Wick MR, Berg LC, Hertz MI. Large cell carcinoma of the lung with neuroendocrine differentiation. A comparison with large cell "undifferentiated" pulmonary tumors. Am J Clin Pathol. 1992;97(6): 796-805.

28. Jiang SX, Kameya T, Shoji M, Dobashi Y, Shinada J, Yoshimura H. Large cell neuroendocrine carcinoma of the lung: a histologic and immunohistochemical study of 22 cases. Am J Surg Pathol. 1998; 22(5):526-537.

29. Roesel C, Terjung S, Weinreich G, et al. A single-institution analysis of the surgical management of pulmonary large cell neuroendocrine carcinomas. Ann Thorac Surg. 2016;101(5):1909-1914.

30. Albores-Saavedra J, Gersell D, Gilks CB, et al. Terminology of endocrine tumors of the uterine cervix: results of a workshop sponsored by the College of American Pathologists and the National Cancer Institute. Arch Pathol Lab Med. 1997;121(1):34-39.

31. Gilks CB, Young RH, Gersell DJ, Clement PB. Large cell neuroendocrine [corrected] carcinoma of the uterine cervix: a clinicopathologic study of 12 cases. Am J Surg Pathol. 1997;21(8):905-914.

32. Saji H, Tsuboi M, Matsubayashi J, et al. Clinical response of large cell neuroendocrine carcinoma of the lung to perioperative adjuvant chemotherapy. Anticancer Drugs. 2010;21(1):89-93. 
33. Iyoda A, Hiroshima K, Moriya Y, et al. Prospective study of adjuvant chemotherapy for pulmonary large cell neuroendocrine carcinoma. Ann Thorac Surg. 2006;82(5):1802-1807.

34. Sarkaria IS, Iyoda A, Roh MS, et al. Neoadjuvant and adjuvant chemotherapy in resected pulmonary large cell neuroendocrine carcinomas: a single institution experience. Ann Thorac Surg. 2011;92(4):1180-1186. discussion 1186-1187.

35. Malapelle U, Morra F, Ilardi G, et al. USP7 inhibitors, downregulating CCDC6, sensitize lung neuroendocrine cancer cells to PARP-inhibitor drugs. Lung Cancer. 2017;107:41-49.

36. Iyoda A, Hiroshima K, Moriya Y, et al. Postoperative recurrence and the role of adjuvant chemotherapy in patients with pulmonary large-cell neuroendocrine carcinoma. J Thorac Cardiovasc Surg. 2009;138(2): 446-453.

37. Kenmotsu $\mathrm{H}$, Niho S, Ito T, et al. A pilot study of adjuvant chemotherapy with irinotecan and cisplatin for completely resected high-grade pulmonary neuroendocrine carcinoma (large cell neuroendocrine carcinoma and small cell lung cancer). Lung Cancer. 2014;84(3):254-258.

38. Kenmotsu Y, Oshita F, Sugiura M, et al. Nedaplatin and irinotecan in patients with large-cell neuroendocrine carcinoma of the lung Anticancer Res. 2012;32(4):1453-1456.

39. Kim KW, Kim HK, Kim J, Shim YM, Ahn MJ, Choi YL. Outcomes of curative-intent surgery and adjuvant treatment for pulmonary large cell neuroendocrine carcinoma. World J Surg. 2017;41(7):1820-1827.

40. Ahmad SI, Kirk SH, Eisenstark A. Thymine metabolism and thymineless death in prokaryotes and eukaryotes. Annu Rev Microbiol. 1998;52:591-625.

41. Adjei AA. Pharmacology and mechanism of action of pemetrexed Clin Lung Cancer. 2004;5(suppl 2):S51-S55.

42. Heidelberger C, Chaudhuri NK, Danneberg P, et al. Fluorinated pyrimidines, a new class of tumour-inhibitory compounds. Nature. 1957; 179(4561):663-666.
43. Hanna N, Shepherd FA, Fossella FV, et al. Randomized phase III trial of pemetrexed versus docetaxel in patients with non-small-cell lung cancer previously treated with chemotherapy. J Clin Oncol. 2004;22(9):1589-1597.

44. Scagliotti GV, Parikh P, von Pawel J, et al. Phase III study comparing cisplatin plus gemcitabine with cisplatin plus pemetrexed in chemotherapy-naive patients with advanced-stage non-small-cell lung cancer. J Clin Oncol. 2008;26(21):3543-3551.

45. Scagliotti G, Hanna N, Fossella F, et al. The differential efficacy of pemetrexed according to NSCLC histology: a review of two phase III studies. Oncologist. 2009;14(3):253-263.

46. Ceppi P, Volante M, Saviozzi S, et al. Squamous cell carcinoma of the lung compared with other histotypes shows higher messenger RNA and protein levels for thymidylate synthase. Cancer. 2006; 107(7):1589-1596.

47. Ceppi P, Volante M, Ferrero A, et al. Thymidylate synthase expression in gastroenteropancreatic and pulmonary neuroendocrine tumors. Clin Cancer Res. 2008;14(4):1059-1064.

48. Zheng Z, Li X, Schell MJ, et al. Thymidylate synthase in situ protein expression and survival in stage I nonsmall-cell lung cancer. Cancer. 2008;112(12):2765-2773.

49. Ishihama H, Chida M, Araki O, et al. Comparison of 5-fluorouracilrelated gene expression levels between adenocarcinomas and squamous cell carcinomas of the lung. Jpn J Clin Oncol. 2009;39(1): 33-36.

50. Vogelzang NJ, Rusthoven JJ, Symanowski J, et al. Phase III study of pemetrexed in combination with cisplatin versus cisplatin alone in patients with malignant pleural mesothelioma. J Clin Oncol. 2003; 21(14):2636-2644.
OncoTargets and Therapy

\section{Publish your work in this journal}

OncoTargets and Therapy is an international, peer-reviewed, open access journal focusing on the pathological basis of all cancers, potential targets for therapy and treatment protocols employed to improve the management of cancer patients. The journal also focuses on the impact of management programs and new therapeutic agents and protocols on

\section{Dovepress}

patient perspectives such as quality of life, adherence and satisfaction. The manuscript management system is completely online and includes a very quick and fair peer-review system, which is all easy to use. Visit http://www.dovepress.com/testimonials.php to read real quotes from published authors. 